EPJ Web of Conferences 33, 04005 (2012)

DOI: $10.1051 /$ epjconf/20123304005

(C) Owned by the authors, published by EDP Sciences, 2012

\title{
Travelling Wave Based Fault Location Analysis for Transmission Lines
}

\author{
L. de Andrade ${ }^{1, \mathrm{a}}$, and T. Ponce de Leão ${ }^{2}$ \\ ${ }^{1}$ UPorto, Faculdade de Engenharia, Rua Dr. Roberto Frias, s/n 4200-465 Porto, Portugal \\ ${ }^{2}$ LNEG, Estrada da Portela, Bairro do Zambujal Ap.7586 2720-866 Amadora, Portugal
}

\begin{abstract}
This paper presents a review of the state of the art for fault location methods in transmission lines based on travelling waves. The motivations that led to these methods are explained historically. Also, a critical analysis, showing the advantages and disadvantages of each of them and their most common applications, is performed. Finally, a comparative analysis between two of the most widely used methods is carried out using real faults, in order to show the results' sensitivity to changes in the line parameters.
\end{abstract}

\section{Introduction}

Even the best planned systems are subject to unpredictable events in transmission lines that place the system beyond the planned limits. When a major power system disturbance occurs, protection and control actions need to take place in order to prevent power system degradation and restore the system to a normal state within a minimum time. But in most cases, the service outages of these lines inevitably lead to the loss of large blocks of loads. So, a quick repair for the line service recovery is vital for the system operators.

The operators must therefore deal with a very complex situation where they perform a series of procedures to achieve breakdown service. These procedures always carry a significant expenditure of time.

Most lines inevitably cross through complex terrain, and work under difficult weather conditions, so the time required to physically check the lines is long. However, researches about fault location techniques for transmission lines show that accurate and fast methods are of great significance and of practical engineering value $[1,2]$. Prompt and accurate fault location in transmission lines can accelerate the system restoration, reduce the outage time and improve the system reliability.

In general, all fault location methods can be classified according to Figure 1. This paper will be focused on travelling wave-based methods. This paper complements other work which contains a review of the impedance-based methods [3]. With both papers, a review of the current state of the art of fault locators is reached.

This paper aims to show the efforts made to meet the needs of fault location in transmission lines that exist in the modern power systems. For this, the paper addresses the issue in two ways, one theoretical and other practical. In the theoretical part, a general definition of fault location is presented and a critical analysis of different methods is made; showing the advantages and

a e-mail : luis.de.andrade@fe.up.pt

This is an Open Access article distributed under the terms of the Creative Commons Attribution License 2.0, which permits unrestricted use, distribution, and reproduction in any medium, provided the original work is properly cited. 


\section{EPJ Web of Conferences}

disadvantages of each of them and their most common applications. In the practical part, a comparative analysis between two of the most widely used methods is made, using faults tests as examples to show the sensitivity results to changes in the fault records sampling rate.

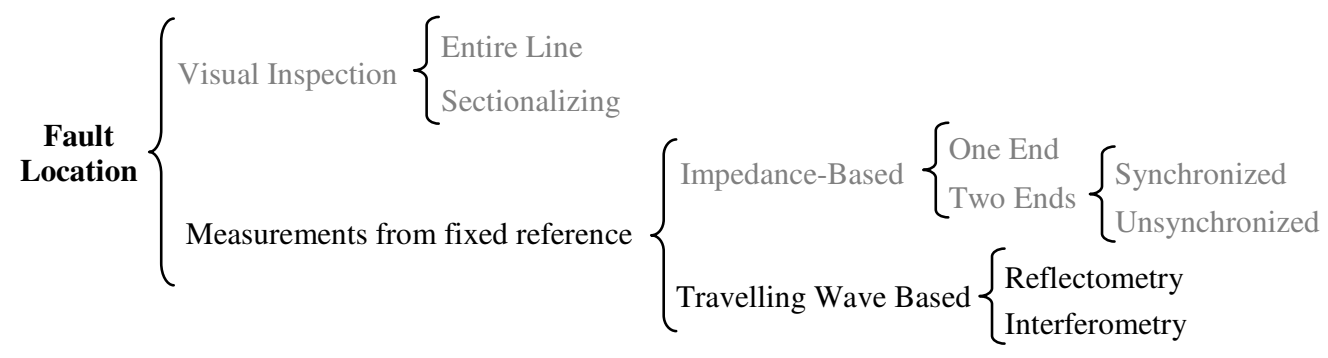

Fig. 1. Classification of transmission line fault location methods.

\section{Fault locations definition}

The problem of locating transmission line faults is as old as the power industry itself. In the beginning, the fault location was made directly by visual inspections of the line. But the visual inspection of a long line, both on foot or by air, is always extremely slow and is subject to the terrain circumstances and environmental conditions of the moment. Additionally, visual inspection does not always ensure that the location will be found because, in many cases, faults don't let physical evidence.

The fault location techniques, are a group of techniques that seek to locate, with the highest possibly accuracy, all those abnormal network conditions that takes the current out of its normal course through a transmission line. These techniques are used before starting the visual inspection, so that the work area can be delimited to a small section of the line.

For the location, these techniques are based on the impact that faults have on other well-defined points on the same line. In these other previously defined points, different types of data are collected and analyzed to conclude that only an event with certain characteristics may have such effects on the measuring point. The location of this event is the fault location.

Many methods have been developed about fault location in transmission lines and many papers have been published about each of these methods. The researches discussed below are all pioneers in their respective work areas and all are representative samples of development that have occurred in the different fault location methods.

\section{Travelling wave based fault location}

The travelling-wave based fault location was first proposed by Röhrig in 1931 [4]. Its use was implemented initially in the middle of the 20th century by Stevens and Lewis [5, 6] but they were gradually abandoned 1970 s later due to their high cost, poor reliability and maintenance problems. In general, the methods are founded on the work of Carson [7, 8] and are based on measure the time that takes the wavehead to propagate from the point where a discontinuity occurs in the line to the measuring terminals. If the speed by which the wave travels is known, then is possible to calculate how much distance the wavehead has travelled.

In the middle of $1980 \mathrm{~s}$, the interest for travelling wave methods was renewed by SEL Inc. and other papers were published to employ this technique for fault location [9-11]. A technique for locating faults using information from only one end of the line is developed in [9, 10]. This method uses successive reflections generated by faults (reflectometry technique). In many cases, there are large impedance mismatches when a fault starts, this generates transient waves that travel through the line and are reflected between the fault and the line ends. From measurements of the first two 


\section{$2^{\text {nd }}$ European Energy Conference}

consecutive transient arrival times, the fault location can be calculated. Because the method only uses information from one end line, the key is the observation of the relative polarity of the two waveheads generated by the fault and propagated towards each end-line. So is possible to differentiate the wavehead originating from one end-line and those reflected from the opposite end.

On the other hand, in [11] is developed a technique by Dewe et al. for location using information from both ends of the line. By having information available at both ends, the analysis is facilitated. In this method, the analysis is based on the time difference in the arrival of the fault-generated wave at each end of the line. The simultaneous processing of information from both ends is achieved by a very accurate data acquisition with the time reference signals provided by a global positioning system receiver.

Since then, others travelling wave-based methods were developed, where travelling wave method and other known methods were combined to facilitate the detections and fault analysis. Like the method proposed by Magnago et al. in [12], which uses the wavelet transform to improve the wavehead detection, because it allows time localization of different frequency components of a given signal

After the 1990s, with the developments of communication systems and digital signal processing techniques, the travelling wave based fault location techniques got more and more applications in different AC transmission systems. But these methods are mostly used for HVDC lines than for AC systems. In fact, fault location methods implemented on HVDC lines are all based on travelling wave without exception. Some examples of these are [13-15]. In [13] is proposed by Murthy et al. a method for fault location in HVDC lines using wavelet transforms. The ability of the wavelet transform to locate both time and frequency makes it possible to simultaneously determine the sharp transitions of signals and the location of their occurrence.

Other method is proposed by Ping et al. in [14], combining the single-end and two-ends methods. With this combination, the aim is to complement the results of both methods. This will reduce the amount of cases where each method separately is not sufficient or has problems in locating the fault. And in [15] is proposed by Young-Jin et al. a combination between a travelling wave with a cross correlation methods for locations on HVDC cable lines. To detect the wavehead, it's used the cross correlation method, based on the similarity between the first wavehead (used as the template signal) and a subsequent wavehead, both measured at the same line end. If two signals have the same shape, the correlation result would be maximum.

All these travelling wave-based methods have a fast response and high accuracy. However, they are also facing some insurmountable technical problems:

- The detection of the wavehead is the key to travelling wave fault location. If the wavehead cannot be captured successfully, or the wavehead does not exist at all at the occurrence of a fault, the fault location will fail. For instance, when the line is grounded through a large resistance, the transient travelling wave signals are too weak to be detected, disabling the fault location under these circumstances. Moreover, if a fault is caused by a gradual change in the transition resistance, the travelling wave may also be too weak to be discovered, resulting in the failure of the fault location [9-12, 14-16].

- In these methods, is measured the time it takes the wavehead to arrive at the point where the device is installed, and the fault distance is the product of the time and the wave speed. Therefore, the accuracy of the fault location is dependent, to a great extent, on the wave speed, and since the wave speed is $v_{t}=1 / \sqrt{L C}$ (where $L$ is the inductance and $C$ is the capacitance of the propagation medium) this methods also depends of the line parameters [14-16].

- Accuracy in fault location depends upon sampling frequency. Since the speed at which the wave travels over transmission lines is slightly lower than light speed, in order to achieve higher accuracy, a very high sampling frequency has to be used in travelling wave fault location methods. Therefore, more expensive and complex equipments are required $[11,16]$.

- The wavehead must be identified to locate the fault, which is often carried out by experienced professionals and cannot be implemented automatically by computers [1]. 


\section{EPJ Web of Conferences}

- Since the travelling wave fault location uses the signal high frequency components for the analysis, is vulnerable to interference of external signals $[11,14]$.

- If the fault occurs near a line end, is very difficult to identify the wavehead with information of this line end due to the high speed of the travelling wave $[12,13,15,16]$.

- Another difficulty arises for faults near the buses or for those faults occurring at near zero voltage inception angle because, if the voltage is zero when the fault starts, there is not an abrupt change of the line continuity and a wavehead is not produced $[12,13,15,16]$.

Table 1 shows a summary of all the fault location methods discussed here.

Table 1. Fault location methods summary.

\begin{tabular}{|c|c|c|c|c|c|c|c|}
\hline 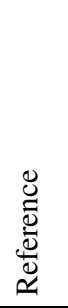 & 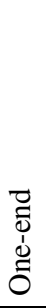 & 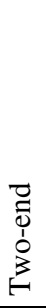 & 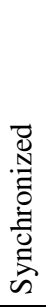 & 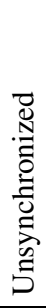 & 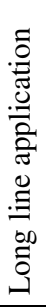 & 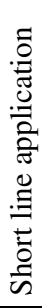 & 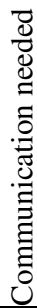 \\
\hline [5] & $\bullet$ & & & $\bullet$ & $\bullet$ & & \\
\hline [6] & $\bullet$ & & & $\bullet$ & $\bullet$ & & \\
\hline [9] & $\bullet$ & & & $\bullet$ & $\bullet$ & - & \\
\hline$[10]$ & $\bullet$ & & & $\bullet$ & $\bullet$ & - & \\
\hline [11] & & $\bullet$ & $\bullet$ & & $\bullet$ & & $\bullet$ \\
\hline [12] & & $\bullet$ & $\bullet$ & & $\bullet$ & & - \\
\hline [13] & $\bullet$ & & & $\bullet$ & $\bullet$ & & \\
\hline [14] & & - & $\bullet$ & & $\bullet$ & & - \\
\hline$[15]$ & $\bullet$ & & $\bullet$ & & $\bullet$ & & - \\
\hline
\end{tabular}

\section{Comparative analyses}

Most of the literature indicates the need for high sampling rate of fault records as one of the main disadvantages of travelling wave methods, but do not show quantitative results to support it.

In order to evaluate this statement, this paper presents a sensitivity analysis, comparing the results of two methods. For the test, two of the most widely accepted methods were used. First, a one-end method based on spectrum estimation [17], and then a two-end method based on wavelet [12].

The test consists in analyzing a fault repeatedly but using records with different sampling rate. The records sampling rate varies from $2 \mathrm{kHz}$ to $5 \mathrm{MHz}$. The test was performed for both selected methods in order to compare the results.

Simulated faults were used for the analysis in order to study the sensitivity of these methods to variations in the frequency of sampling fault records. For this analysis, real faults records could not be used, since different records of the same fault are required and also obtained in a wide frequency range. Likewise, is not enough to simulate changes in the records sampling rate by deleting samples, because the results would always be multiples of the original record and would not allow the integral study of all possible frequencies.

The fault was simulated using MatLab ${ }^{\circledR}$. The power system was based on two parallel $735 \mathrm{kV}$ transmission lines with $500 \mathrm{~km}$ length and two different equivalents systems, one at each line end. Both lines were modelled using the distributed parameter line model. The analyzed event was a monophasic fault at $200 \mathrm{~km}$ from bus A as is shown on Figure 2.

In order to make comparisons between records, the results are not shown in distance values $(\mathrm{km})$, but referred to as percentage errors based on the total distances of the lines (\%) as indicated in [18]. 


\section{$2^{\text {nd }}$ European Energy Conference}

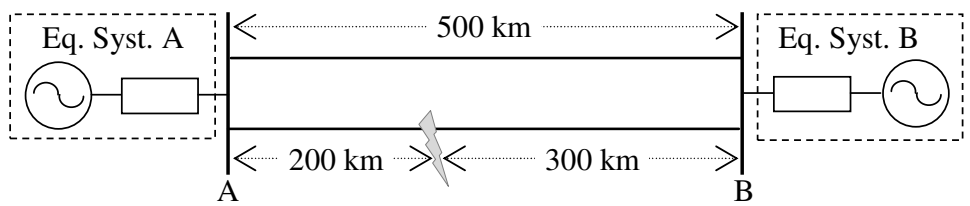

Fig. 2. Simulated power system model.

The fault distance was chosen to ensure that the incident and reflected wavehead do not coincide when arriving at each line end and, therefore, they can be clearly distinguishable at the analysis, as shown in the Lattice diagram of Figure 3.

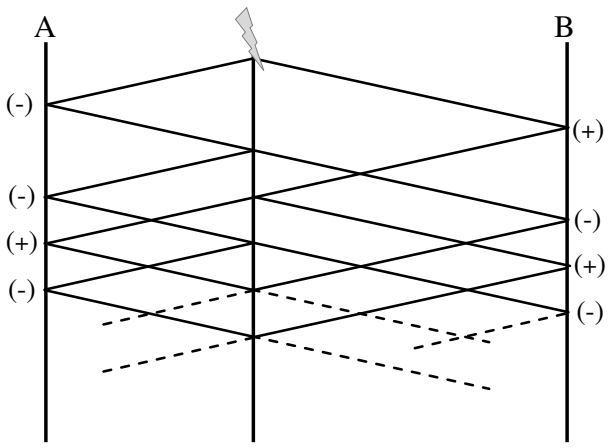

Fig. 3. Simulated fault Lattice diagram.

In three phase transmission lines, the travelling waves are coupled and a single wave velocity does not exist. In order to implement these methods in three phase systems, the phase domain signals are first decomposed into their modal components [12]. In this study, all line models are assumed to be fully transposed, and therefore the well known Clarke's constant and real transformation matrix is used:

$$
S_{\text {mode }}=\frac{1}{3}\left[\begin{array}{ccc}
1 & 1 & 1 \\
2 & -1 & -1 \\
0 & \sqrt{3} & -\sqrt{3}
\end{array}\right] S_{\text {phase }}
$$

Where $S_{\text {phase }}$ and $S_{\text {mode }}$ are the phase signal and mode signal components, respectively.

Simulated records phase signals are first transformed into their modal components and the mode 2 is taken for analysis. The second mode (mode 2), also known as the aerial mode, is the most common mode used in this type of analysis since is present for any kind of fault.

In order to illustrate the tests, Figure 4 and Figure 5 show the voltages and currents records for both line ends during the fault. As records show, the fault begins intentionally far from the wave peak and zero crossing, in order to achieve a higher break in the continuity of the medium as possible. Also, is possible to see how travelling waves appear in the phases without fault due to mutual coupling effect between phases.

Currents from the A line-end were used for the analysis with spectrum estimation method, and currents from both line ends were used for the analysis with wavelet method. Both methods are based on decomposing the fault records into the frequency components that exist in the signal. For this, the Fourier transform was used in the first method, and wavelet transform in the second method. 


\section{EPJ Web of Conferences}
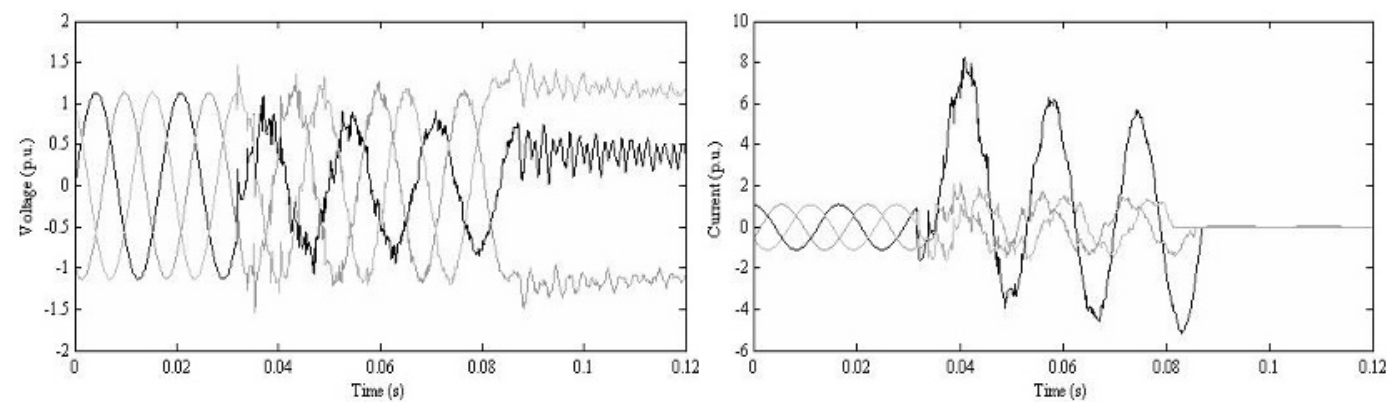

Fig. 4. Voltages and currents signal for the A line-end.
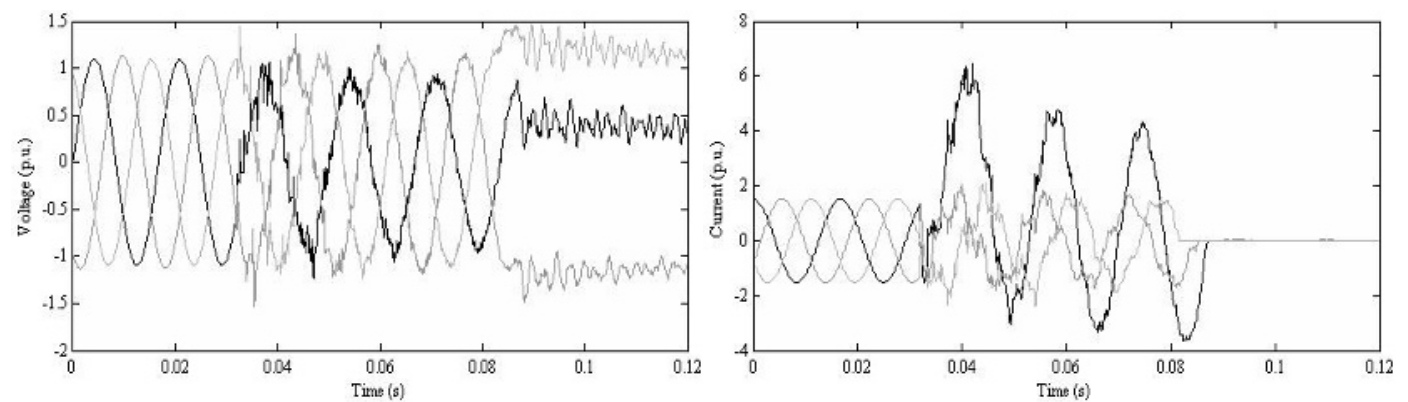

Fig. 5. Voltages and currents signal for the B line-end.

With the Fourier transform is possible to see the different frequencies that compose the signal. Knowing which is the predominant frequency in the signal (besides the fundamental frequency), the time that takes the wavehead to travel from the line end to the fault point can be calculated and then the fault location is known.

With the wavelet transform, is possible to know not only the signal frequency components but also at what time they appear. Comparing these times with those of the opposite extreme, is easy to know the fault location.

Figure 6 and Figure 7 show two typical results obtained with each method for the same fault. These methods are applied repeatedly on the same fault, but using records with different sampling rate. The sensitivity analysis results of the methods against these variations are shown on the next section.

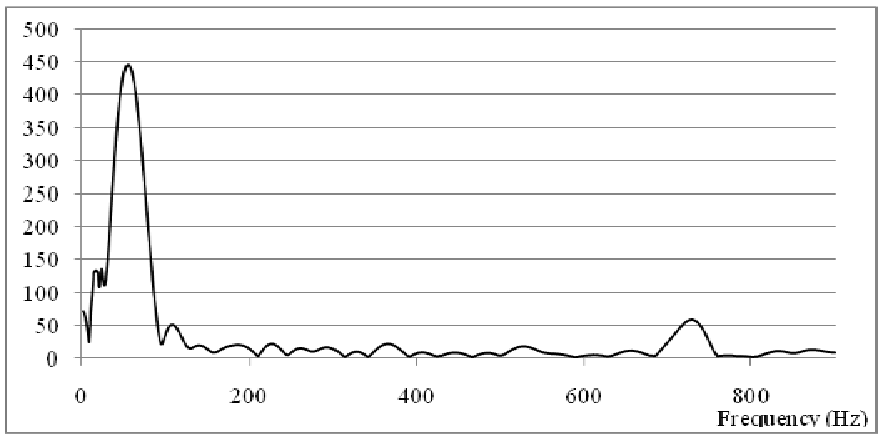

Fig. 6. Fourier transform example for fault records. 


\section{$2^{\text {nd }}$ European Energy Conference}

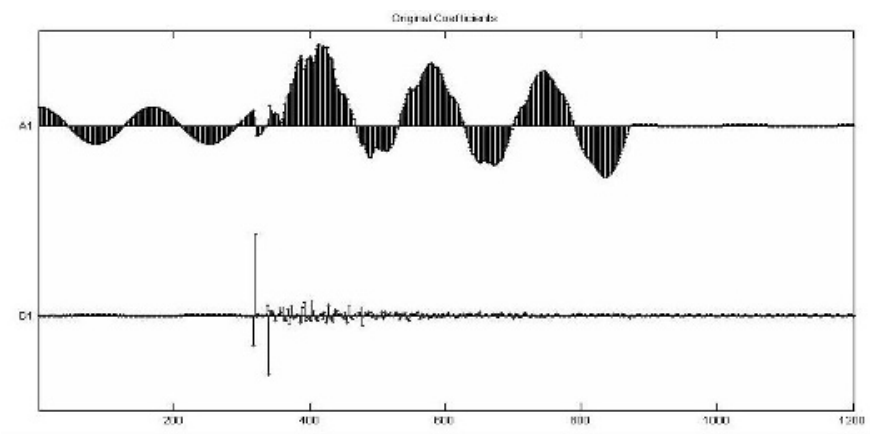

Fig. 7. Wavelet transform example for fault records.

\section{Test Results}

Figure 8 shows the test results obtained with variations of the records sampling rate for the spectrum estimation and wavelet methods, and also shows the minimum theoretical error. All results are presented using the distance from the A line end as reference.

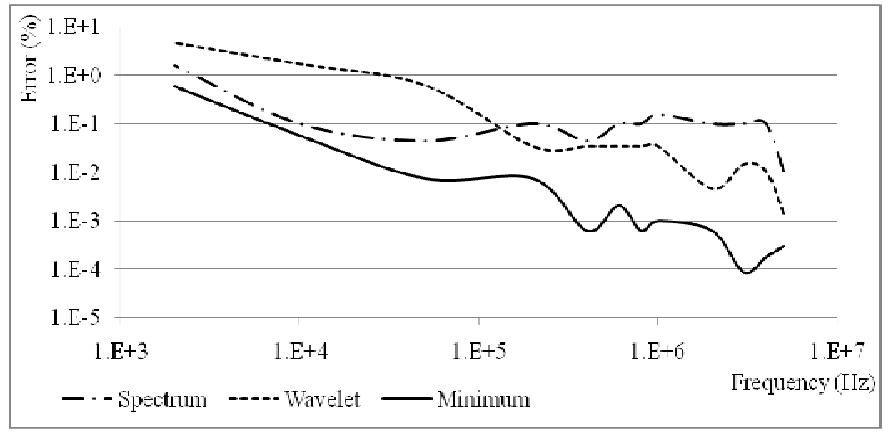

Fig. 8. Records sampling rate variation test results.

The minimum theoretical value for the errors was calculated for this specific fault based on the fault's start time, the distance to "A" line end, the travelling wave speed, and the different records sampling rate. On this basis, results beyond expectations are given such as the minimum error possible with $5 \mathrm{MHz}$ (the biggest frequency tested) is greater than with $3 \mathrm{MHz}$ (the smallest error point in the line) because the wavehead reaches to end "A" just between two samplings in the case of $5 \mathrm{MHz}$. In the case of $3 \mathrm{MHz}$, the arrival of the wavehead coincides precisely with a sample, so the precision in the analysis increases.

In practice, many factors avoid that errors as low as expected theoretically can be obtained. Among the main factors are the signal analysis windows for frequency and time. Since the signal transforms are a function of both time and frequency, the exact time-frequency representation of a signal cannot be known, i.e., is not possible to know what spectral components exist at what instances of times, but to know the time intervals in which certain band of frequencies exist, which is a resolution problem. This fact is known as the Heisenberg Uncertainty Principle.

Regarding the analyzed methods, is possible to observe that the spectrum estimation method is less sensitive to sample rate variations than the wavelet method. To low sample rate tests, the lower errors were obtained with the spectrum estimation method. While for high sample rate tests, the lower errors were obtained with the wavelet method.

The results are in line with the main statement, because in general the errors are bigger as the records sample rate decreases. 
EPJ Web of Conferences

\section{Conclusions}

This paper presents a general overview about fault location on transmission lines.

It describes the fundamental principles of the travelling wave fault location methods, and comparisons are made between the advantages and disadvantages of each of the different methods. This is useful for final users when selecting the one that's most convenient and that best suits the available technology. Finally, a comparative analysis is performed between two of these methods, based on changes in the fault records sampling rate.

In general, is considered that the methods that use information from both line ends are more robust than methods that use information from only one line end. Although in general, this statement is well founded, this paper demonstrated that is not absolutely correct since the two-end method proved to be more sensitive to the variations that the one-end method. In any case, these results are not alarming since differences between errors are very small, and also the two-end methods have better results at higher sample rates which are the most common used samples for the traveling wave fault location methods. But in some cases this needs to be clarified in order to avoid confusions.

The most important thing is to really know the different fault location methods in order to select the one that best suits the available resources.

\section{Appendix}

Appendix A: transmission system data used in the comparative analysis of section 4 .

Table A1. Transmission line parameters.

\begin{tabular}{|c|c|c|}
\cline { 2 - 3 } \multicolumn{1}{c|}{} & \multicolumn{2}{c|}{$735 \mathrm{kV}$ Line } \\
\hline Parameter & Seq,+- & Seq 0 \\
\hline Resistance $(\Omega / \mathrm{km})$ & 0.01165 & 0.2676 \\
\hline Inductance $(\mathrm{H} / \mathrm{km})$ & $0.8679 \mathrm{e}-3$ & $3.008 \mathrm{e}-3$ \\
\hline Capacitance $(\mathrm{F} / \mathrm{km})$ & $13.41 \mathrm{e}-9$ & $8.57 \mathrm{e}-9$ \\
\hline
\end{tabular}

Table A2. Equivalent power system data.

\begin{tabular}{|c|c|c|}
\cline { 2 - 3 } \multicolumn{1}{c|}{} & \multicolumn{2}{c|}{ Equivalent system } \\
\hline Data & A & B \\
\hline Frequency $(\mathrm{Hz})$ & 60 & 60 \\
\hline Voltage $(\mathrm{kV})$ & 735 & 735 \\
\hline Resistance $(\Omega)$ & 5.3754 & 2.6877 \\
\hline Reactance $(\Omega)$ & 53.7544 & 26.8772 \\
\hline
\end{tabular}

A monophasic solid bolted fault in phase A of the line was simulated on this system. The fault begins at $0.031 \mathrm{sec}$. after the simulation starts and the line is opened at $0.05 \mathrm{sec}$. after that. Both line ends are opened simultaneously.

\section{References}

1. P. Gale, J. Stokoe, P. Crossley, Practical experience with travelling wave fault locators on Scottish Power's 275 \& 400 kV transmission system in Sixth International Conference on Developments in Power System Protection, 434, 192-196 (1997)

2. L. de Andrade, R. Guanipa, Costs Reduction in Attention to Transmission Lines Faults Using

Faults Location Equipment in I Congreso Venezolano de Redes y Energía Eléctrica (2007) 


$$
2^{\text {nd }} \text { European Energy Conference }
$$

3. L. de Andrade, T. Ponce de Leão, Impedance-Based Fault Location Analysis for Transmission Lines in IEEE PES Transmission and Distribution Conference, (2012)

4. J. Röhrig, Location of faulty places by measuring with cathode ray oscillographs, Elektrotech Zeits, 8, 241-242 (1931)

5. R. F. Stevens, T. W. Stringfield, A Transmission Line Fault Locator Using Fault-Generated Surges, Transactions of the American Institute of Electrical Engineers, 67, 1168-1179 (1948)

6. L. J. Lewis, Traveling Wave Relations Applicable to Power-System Fault Locators, Transactions of the American Institute of Electrical Engineers, 70, 1671-1680 (1951)

7. J. R. Carson, Theory of the Transient Oscillations of Electrical Networks and Transmission Systems, Transactions of the American Institute of Electrical Engineers, XXXVIII, 345-427 (1919)

8. J. R. Carson, Wave Propagation in Overhead Wires with Ground Return, Bell System Technical Journal, 5, 539-554 (1926)

9. M. Ando, E. Schweitzer, R. Baker, Development and Field-Data Evaluation of Single-End Fault Locator for Two-Thermal HVDC Transmission Lines Part I: Data Collection System and Field Data, IEEE Transactions on Power Apparatus and Systems, PAS-104, 3524-3530 (1985)

10. M. Ando, E. Schweitzer, R. Baker, Development and Field-Data Evaluation of Single-End Fault Locator for Two-Terminal HVDC Transmission Lines Part 2: Algorithm and Evaluation, IEEE Transactions on Power Apparatus and Systems, PAS-104, 3531-3537 (1985)

11. M. Dewe, S. Sankar, J. Arrillaga, The Application of Satellite Time References to HVDC Fault Location, IEEE Transactions on Power Delivery, 8, 1295-1302 (1993)

12. F. H. Magnago, A. Abur, Fault location using wavelets, IEEE Transactions on Power Delivery, 13, 1475-1480 (1998)

13. P. Murthy, J. Amarnath, S. Kamakshiah, B. Singh, Wavelet Transform Approach for Detection and Location of Faults in HVDC System, in IEEE Third international Conference on Industrial and Information Systems, Region 10, 1-6 (2008)

14. C. Ping, X. Bingyin, L. Jing, A Traveling Wave Based Fault Locating System for HVDC Transmission Lines, in International Conference on Power System Technology, 1-4 (2006)

15. K. Young-Jin, K. Sang-Hee, L. Dong-Gyu, K. Hyung-Kyu, Fault Location Algorithm Based on Cross Correlation Method for HVDC Cable Lines, in IET 9th International Conference on Developments in Power System Protection, 360-364 (2008)

16. T. Kawady, J. Stenzel, Investigation of practical problems for digital fault location algorithms based on EMTP simulation, in IEEE/PES Transmission and Distribution Conference and Exhibition 2002: Asia Pacific, 1, 118-123 (2002)

17. E. Styvaktakis, M. Bollen, I. Y. H. Gu, A fault location technique using high frequency fault clearing transients, IEEE Power Engineering Review, 19, 58-60 (1999)

18. IEEE, IEEE Guide for Determining Fault Location on AC Transmission and Distribution Lines, in IEEE Std C37.114-2004, 1-36 (2005) 